\title{
Reclamation Measures to Ensure the Reliability of Soil Fertility
}

\author{
Yurchenko Irina F. \\ Doctor of Technics, associate professor \\ FSBSRE All-Russia Research Institute of Hydraulic \\ Engineering and Reclamation by the name \\ of A.N. Kostyakov \\ Moscow, Russia \\ e-mail: irina.507@mail.ru

\section{Volosukhin Victor A.} \\ Doctor of Technics, professor \\ FSBEI HE Platov South-Russian State \\ Polytechnic University (SRPU) \\ Novocherkassk, Rostov region, Russia \\ e-mail: ngma_str_meh@mail.ru
}

\author{
Bandurin Mikhail A. \\ Doctor of Technics, associate professor \\ FSBEI HE Platov South-Russian State \\ Polytechnic University (SRPU) \\ Novocherkassk, Rostov region, Russia \\ e-mail: chepura@mail.ru
}

\author{
Mikheyev Alexander V. \\ Candidate of Technics, associate professor \\ FSBEI HE Platov South-Russian State \\ Polytechnic University (SRPU) \\ Novocherkassk, Rostov region, Russia \\ e-mail: avmih@mail.ru
}

\begin{abstract}
The analysis of farming systems functioning on reclaimed lands shows the need to improve their operation, based on the greening of reclamation activities, primarily within the protection of soil from degradation, its preservation and reproduction of soil fertility. Modernization of procedures for planning a set of engineering, agrotechnical and organizational measures concerning technical exploitation of reclamation systems to prevent negative impacts on the components of agrolandscapes should meet the following priority requirements: increase in the importance of assessing the social and environmental consequences of the activities concerning the repair and care of the reclamation water sector facilities; regulation of the natural environment reproduction in terms of quantitative economic growth; co-organization of land reclamation and agricultural operations; improvements in information support of decision-makers. The measures of improving the technical and investment policy of reclamation activity are proposed through development and introduction of innovative methods to distribute limited resources in the field of operation, providing optimization of agricultural soil fertility reliability, as an indicator of efficiency of the planned-preventive measures of reclamation systems technical operation. With the correct use of the source data and the implementation of calculations, the recommended approach to appoint repair and maintenance of the system of complex melioration and reclamation preparation of areas will increase the accuracy of
\end{abstract}

reflection of complex processes that lead to the change of soil fertility of agricultural lands. Implementation of the proposed directions for optimization of management decisions within the information technology will provide a wide range of users with the opportunity of practical using innovative methods in the field of land reclamation.

Keywords-reclamation measures, the reliability of soil fertility, an indicator of efficiency, reclamation water industry.

\section{INTRODUCTION}

The activities of integrated melioration are becoming a recognized factor in ensuring the sustainability of agricultural production [1], which is characterized by the desire to obtain high production results while reducing anthropogenic pressure on the natural environment. The requirements for preservation and reproduction of the components of the natural environment of reclaimed agro-landscapes are implemented in the Russian Federation in the specific conditions of solving problems of food security and import substitution [2]. The emerging need for a substantial increase in agriculture production of food impedes the conservation and enhancement of the natural potential of agricultural landscapes. 
In this regard, the urgency of reforming the reclamation activities strategy and improving the exploitation system of reclamation facilities [3] to solve the problem of agricultural production efficiency, an integral part of which is the inexhaustible natural environment [4].

Forming a system of efficiency indicators and criteria is a constant problem at the strategic level of the reclamation sector management, the solution of this task ultimately determines its competitiveness and viability. But today the price of the issue has increased manifold in view of the transformation of the national economy [5] and the targets of land reclamation caused by the queries of constantly high and safe crop production on the reclaimed lands [6].

The most important factor in stabilizing basic productivity of agrocenosis and soil fertility of the reclaimed land is the technical condition of hydro-technical and meliorative objects [7]. Procedures for repair and maintenance of reclamation facilities, related to adjustable factors for preserving and reproducing soil fertility of the reclaimed land and nature conservation [8], provide execution of control actions: Water supply and drainage, saline lands rinsing, drenching elimination, flooding, overheating, irrigation erosion, etc. [9].

The economic, ecological and social efficiency of applying alternative measures of technical exploitation of the objects under reclamation, preventing soil degradation and productivity decrease in agrocenosis may differ significantly. The cost of required preventive measures, as a rule, exceeds the available funding [10].

In such a situation, an effective measure of improving the quality of global and domestic management practices includes an effective optimization solution [11], which determines the need to establish indicators and criteria of its optimality. The indicators used in the field of land reclamation to assess the impact of allocating limited funding for the technical operation of reclamation systems are usually monodisciplinary, often considering just economic efficiency as an optimality criterion [12].

The paper presents methodological approaches to the study of the rate of soil degradation as a criterion for efficiency estimation of technical exploitation of reclamation systems [13].

The research is made to improve the technical and investment policy of reclamation activity through [14] development and introduction of innovative methods to distribute limited resources in the field of operation, providing optimization of agricultural soil fertility reliability, as an efficiency indicator of the planned-preventive measures of reclamation systems technical operation.

\section{MATERIALS AND METHODS}

The object of research includes soil fertility of the reclaimed land, the subject is the impact of technical exploitation of reclamation systems on soil fertility of agricultural lands.

The authors used the following methods: collection, analysis and synthesis of the existing normative and methodological materials in the field of research; theory of probability and mathematical modelling. In developing the requirements for information support for the creation and operation of new generation irrigation systems, the article took into account the scientifically substantiated recommendations and existing experience in the practical application of information systems for making decisions, which were mentioned in literary, stock and normative-legal sources on creation, introduction and use of information systems for irrigation management, and the results of individual authors' researches in the field of informational support for reclamation activities were also attracted [15].

The research methodology of complex systems of informational support solutions is characterized by a system approach, system research and system analysis [16]. The specificity of the management methodology, due to the characteristics of the object under study, is revealed by mathematical methods of considering operations on the object and the activity of the decision-maker. This approach has not been properly applied for a long time because of the low level of the quantitative analysis methodology among the decisionmakers [17].

Development and implementation of decision support systems are aimed at automating administrative work through a "friendly" interface that does not require a high level of computer literacy from the user and provides informational and technological support of decision-making procedures, led to the increasing relevance of the use of the quantitative analysis methodology in controlling irrigation and drainage systems [18].

\section{THE RESULTS OF STUDIES AND THEIR DISCUSSION}

Based on the analysis of methodical recommendations on the optimality criteria of planning and implementing reclamation activities $[19,20]$, this research provides the effectiveness evaluation of scarce resources allocation to maintain by the maximum value of the permissible period of post repair of soil drainage systems without activities to reduce negative impact on fertility [21].

The valid period $(\mathrm{T})$ is determined by the period from the beginning of the soil use till the onset of the limiting state when any further use in constant fertility conditions is impractical and/or restoring fertility is too expensive [22].

The calculation is based on (1)

$$
T=\frac{1}{a} \ln \frac{F_{\min }}{F\left(t_{0}\right)}
$$

where a is the characteristic of fertility degradation in the initial observation period of $\mathrm{t}_{0}$;

$\mathrm{F}\left(\mathrm{t}_{0}\right)$ is the value of soil fertility in the initial observation period;

$F_{\text {min }}$ is an unacceptable (marginal) value of soil fertility.

The dependence (1) is obtained under the assumption that the soil in the settlement area has the same fertility properties 
which are equal to the average value for the area and time interval.

An indicator of soil fertility is multi-factorial and casual and its full description contains the distribution function. Changing the state of the soil in time is described by the probability of soil transition from one state to another with the help of the model, defined in the theory of probability as the model of "death and reproduction". The withdrawal did not take into account the random nature of the process of fertility reduction caused by differences in geological, hydrological, climatic and other conditions of reclaimed lands [23].

Considering the stochastic nature of the studied process, it is recommended [24] to use mathematical expectation of a random variable $\mathrm{M}(1 / a)$ instead of a magnitude $1 / a$ and the formula (1) takes the form (2):

$$
T=M\left(\frac{1}{a}\right) \ln \frac{F_{n s}}{F\left(t_{k}\right)}
$$

However, the definition of mathematical expectation of a discrete random variable $1 / a$ with a finite number $\mathrm{n}$ of possible values requires the knowledge of the probability of each value. It is practically difficult to perform this because of the lack of long series of actual observations, which have led to a proposal to replace the indicator of soil fertility with the indicator of the agrocenoses productivity. The replacement is fairly correct with unchanged agro-technologies and plant properties [25]. It is established that approximately $50 \%$ of the yield increase is provided by the virtue of variety and technology of cultivation, shading the relationship between yield and soil fertility [26]. However, there exists the rate of soil fertility which is directly linked to productivity [27].

The type of the characteristic dependence of the decrease in the productivity of agricultural crops as a result of the soil fertility degradation, obtained from the results of a synthesis of experimental data [28], is presented in Figure 1.

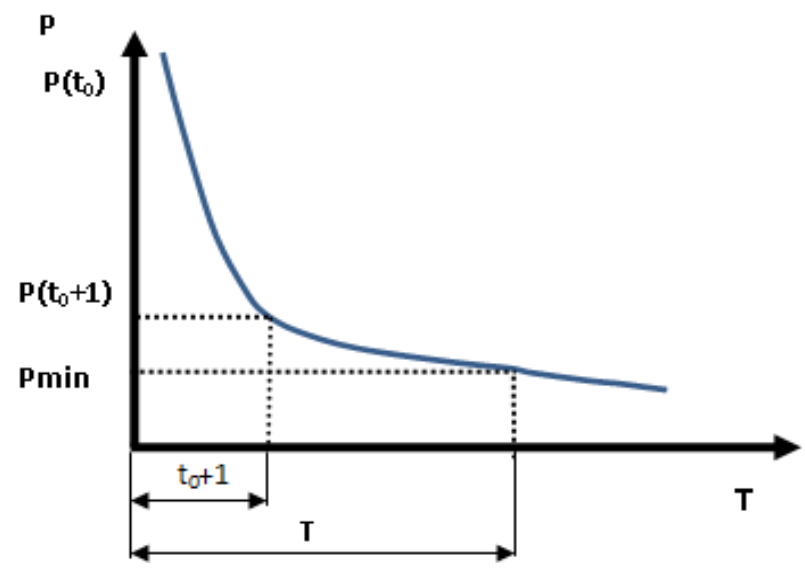

Fig. 1. The productivity reduction of agricultural crops happens as a result of the soil fertility degradation within the system.

$$
P(t)=A \times e^{-B t}
$$

Hence,

$$
t=\frac{1}{B} \ln \frac{A}{P(t)}
$$

Thus, the structures of dependencies (1) and (4) coincide. To determine the parameters $A$ and $B$ we use the following conversions: at $t=T$ the function $P(t)$ takes the value $P_{\min }$, at $t=t_{0} P\left(t_{0}\right)=A$

At $t=t_{0+1}=1$ the function $\mathrm{R}(\mathrm{t})$ can be represented as:

$$
R\left(t_{0+1}\right)=R\left(t_{0}\right) \times K_{d e g}
$$

where $K_{\text {deg }}$ is the factor of fertility decline during the period $\left(t_{0+1}-t_{0}\right)$. At the same time, the formula (3) accounting for the transformations can be represented in the form (6).

$$
R\left(t_{0+1}\right)=R\left(t_{0}\right) \times \mathrm{e}^{-B}
$$

Using the dependence (5) and (6) we get the expression (7) to determine $B$.

$$
B=\ln \frac{1}{K_{\text {дег }}}
$$

The formula (4) after substitution (7) leads to the expression (8) to calculate $\mathrm{T}$.

$$
T=\frac{\ln \frac{P_{\min }}{P\left(t_{0}\right)}}{\ln K_{\partial e 2}}
$$

$K_{d e g}$ is determined using the ratio of annual crop losses $\left(R_{l o s}\right)$ in areas not included in the repair plan, the average crop yields for the system before the repair $R_{a v}$

$$
K_{\text {deг }}=\frac{P_{\text {nom }}}{P_{\text {cp.r. }}}
$$

The length of the rows to determine the average annual yield depends on the period of time during which economic and industrial conditions (agro-technology, technical state of the system, selection, etc.) did not change significantly.

Soil fertility at the beginning of the observation $\mathrm{R}\left(\mathrm{t}_{0}\right)$ is calculated according to the predicted crop after the repair of the complex reclamation systems at the areas. The permissible reduction of crops $P_{\min }$ is set through the expert assessment, as a proportion $(\mathrm{K})$ of the long-term average annual harvest of crops before the renovation of reclaimed areas: 


$$
P_{\text {min }}=K \times R_{a n} ; 0<K<1
$$

The specified approach to the choice of the criterion for evaluating soil degradation as an indicator of the technical exploitation efficiency of reclamation systems is being implemented as a part of a decision support system (DSS) in planning technical operation [29].

DSS in managing complex land reclamation is intended for the determination of preventive measures of technical operation at the objects of complex land reclamation and preparation measures for areas reclamation.

The formation of possible variants and analysis of their optimality is carried out on the basis of simulation. As a calculated option we choose the one which provides the maximum value of the permissible term of the post repair use of soils. Funding of this option is not exceeded, and the total area of the repaired areas and production is not below the minimum possible values.

The discrete model of planning technical operation of complex reclamation systems is presented in the form (11).

$$
T_{j}=>\max
$$

where $T_{\mathrm{j}}$ is the period of achieving unacceptable reduction in soil fertility for the $j$ variant of preventive measures;

$S_{i}$ is the area which is command-by-command subordinate to the $i$ maintenance entity $\left(\mathrm{ME}_{i}\right)$ representing the faulty element of water supply network and/or its constructions; $i=1,2, \ldots N$,

$N$ is the number of ME for the system;

$S$ - the minimum possible area of the repaired parts of the system;

$K i$ - the volume of financing of planning and preventive measures at the i maintenance entity $(\mathrm{ME} i)$;

$K$ - the volume of financing of planning and preventive measures of technical exploitation;

$P i$ - the expected post-repair yield of crops at the areas which are command-by-command subordinate to ME $i$;

$R$ - the minimal acceptable agricultural production at the renovated areas.

$X i j=1$ if $\mathrm{ME} i$ is included in the $j$ repair plan.

otherwise $X i j=0$.

Pilot operation of information system (DSS), conducted by the authors together with the specialists of JSC "Sevkavgiprovodhoz" on irrigation and watering systems operating in the area of the Great Stavropol canal, showed the effectiveness of the proposed approach in the development of maintenance and repair schedules. The effectiveness of DSS is expressed by a set of technical and economic parameters which quantitatively characterize the following constituents of effectiveness [30]:
- indicators of economic efficiency of DSS itself as one of the types of a new technology represented in these studies with the annual economic effect Ean=100.0 thousand rubles and a payback period of total capital investments in additional net income $\mathrm{Tpp}=2$ years;

- the degree of DSS influence on the parameters of the production-economic activities of the organization, calculated in the framework of the pilot operation of the software product by the growth of labor productivity in jobs covered by DSS up to10 \%, and information support of managerial staff up to $20 \%$, and the increase of the automation level up to $10 \%$ and an increase in employment (due to the attraction of personnel conducting the DSS) up to $4 \%$;

- the impact on managerial decisions quality that led to the expected decrease of investment activities for the care and repair of irrigation and drainage systems within the DSS experimental verification - up to $15 \%$, the increase in the productivity of reclaimed agricultural lands - up to $10 \%$.

\section{CONCLUSION}

The research is made to improve the technical and investment policy of reclamation activity through development and introduction of innovative methods to distribute limited resources in the field of operation, providing optimization of agricultural soil fertility reliability, as an efficiency indicator of the planned-preventive measures of reclamation systems technical operation. The object of research includes soil fertility of the reclaimed land, the subject is the impact of technical exploitation of reclamation systems on soil fertility of agricultural lands.

The authors used the following methods: collection, analysis and synthesis of the existing normative and methodological materials in the field of research; theory of probability and mathematical modelling. The methodical approaches to the choice of criteria and assessment of efficiency were defined in the allocation of limited investment in the technical operation of reclamation systems, which ensure high production results of agriculture in the preservation and reproduction of soil fertility. There was created a discrete optimization model of planning technical operation of the reclamation system, implemented in the Information System Environment (DSS) to support management decisions on the development of possible repair, care and other procedures, analysis of their optimality and choice of an effective option. Testing DSS, based on the materials of JSC "Sevkavgiprovodhoz" on technical conditions of irrigation and watering systems operating in the area of the Great Stavropol canal, showed the effectiveness of the proposed approach to develop the maintenance and repair schedules. The annual economic effect in fact is amounted to 100 thousand rubles, while the payback period of the total investment - to 2 years. The growth of labor productivity reaches $10 \%$, information support of managerial staff $-20 \%$, level of automation $-10 \%$ and employment of employees $4 \%$. We obtained, in comparison with the traditional "manual" option, the decline in investing activities for care and repair of 
irrigation and drainage systems - up to $15 \%$, the increase in productivity of reclaimed agricultural lands up to $10 \%$.

Thus, the proposed criteria of assessing soil degradation according to the results of studies include fertility reliability and will allow to solve successfully some practical tasks to optimize planning repair and care for reclamation objects. Its application requires no restrictions on the structure of the factors of negative impact on soil fertility.

\section{References}

[1] B.P. Chesnokov, O.V. Naumova, V.A. Strelnikov, F.K. Abdrazakov, B.A. Tronin, "Polyethylene production from granules using high voltage", International Journal of Applied Engineering Research, vol. 11, pp. 2140-2144, 2016.

[2] I.V. Sharikova, "Land use of agricultural enterprises: problems, trends, prospects (by the example of the Saratov region)", J. National interests: priorities and security, vol. 4 (337), pp. 52, 2016

[3] I.A. Volkova, "Process management of agrarian technologies: methodology and tools", J. Concept, vol 4, pp. 1-5, 2016

[4] I.F. Khitskov, "Problems of sustainable (balanced) development of agrarian - natural systems of the Central Black Earth region", J. Vestnik VSU, Series Economics and Management, vol. 4, pp. 36-43, 2015.

[5] E.B. Kolbachev, M.V. Perederiy, "Planning the development of organizational structures and business processes as an innovative task", Bulletin of the South Russian State Technical University (Novocherkassk Polytechnic Institute). Series: Socio-economic sciences, vol. 1, pp. 4-10, 2015 .

[6] K.A. Anzel'm, "Legal and organizational and economic problems of the operation of the on-farm irrigation network by non-state water holders", J. Bulletin of KazNU, legal series, vol. 50 (2), pp. 273-275, 2016.

[7] D. Seidazimova, T. E. Aitbayev, "Water -Saving Technologies -the Basis for the efficient Development of irrigated vegetable Growing in Kazakhstan" J. Izvestia of the National Academy of the Republic of Kazakhstan, series of agrarian sciences, vol. 2 (32), pp. 73, 2016

[8] Ya. E. Pulatov and others, "Problems of meliorative state of irrigated lands in the Republic of Tajikistan", J. Nature engineering, vol 3, pp. 6 9, 2015.

[9] V.V. Vasiliev, "Optimization of the use of resources in the operation of reclamation systems", J. Bulletin of the Belarusian State Agricultural Academy, vol. 3, pp. 151, 2015

[10] T.I. Safronova, "Substantiation of the method of management of agroresource potential of agrolandscapes", J. Modern problems of science and education, vol 2, pp. 106, 2015.

[11] N.V. Arefiev, K.O. Wenkel, W. Mirschel, V.L. Badenko, V.V. Terleev, Yu.V. Wolf, "Integrated assessment of agro-meliorative systems for planning their reconstruction", J. Mathematical modeling, information technology, measuring systems and methods of precision agriculture, works of the AFI, pp. 468, 2012

[12] V.N. Shchedrin, S.M. Vasiliev, V.V. Slabunov, "The basic rules and regulations for the operation of reclamation systems and structures, water accounting and production operations: monograph", Novocherkassk: Helikon, p. 657, 2013.
[13] M.A. Bandurin, I.F. Yurchenko, V.A. Volosukhin, V.V. Vanzha, Ya.V. Volosukhin, "Ecological and economic efficiency of diagnostics of technical condition of water supply facilities of irrigation systems", J. Ecology and Industry of Russia, vol. 22(7), pp. 66-71, 2018.

[14] L.V. Kireicheva, Scientific foundations of creation and management of reclamation systems in Russia, Moscow: FGBNU VNII agrokhimii, 2017, $296 \mathrm{p}$.

[15] L.V. Kirejcheva, New technologies of designing, substantiation of construction, operation and management of land reclamation systems, Moscow: VNIIA, 2010, $240 \mathrm{p}$

[16] N.F. Ryzhko, F.K. Abdrazakov, S.N. Ryzhko, S.V. Botov, "The increase of qualitative indicators during watering with multiple support sprinklers", Journal of Fundamental and Applied Sciences, vol. 10(6S), pp. 1482-1497, 2018.

[17] I.P. Gaslikova., L.M. Gokhberg, "Information Technology in Russia", Moscow, p. 187, 2002.

[18] A.S. Hmelyak, "Information systems of enterprise management: positive and negative aspects of implementation", J. Actual questions of economic sciences, vol. 35, pp. 186-182, 2013.

[19] H.P. Kerzner, "Project Management A Systems Approach to Planning, Scheduling, and Controlling”, John Wiley \& Sons, Inc. 2013

[20] J.T. Marchewka, "Information Technology Project Management". John Wiley \& Sons, p. 376, 2014.

[21] F.K. Abdrazakov, S.S. Orlova, T.A. Pankova, E.N Mirkina, O.V. Mikheeva, "Risk assessment and the prediction of breakthrough wave during a dam accident", Journal of Interdisciplinary Research, vol. 8(1) pp. 154-161, 2018.

[22] V.I. Olgarenko, I.V. Olgarenko, V.I. Selyukov, "Computer technology of planning water use in irrigation systems", Bulletin of the Russian Academy of Agricultural Sciences, vol. 4, pp. 12-15, 2012

[23] T.U. Nguyen, H.M. Newby, M.J. Macaulay, "Information Technology Adoption in Small Business: Confirmation of a Proposed Framework' Journal of Small Business Management, vol. 53, Issue 1, pp. 207-227, 2015 .

[24] O. Degtyareva, G. Degtyarev, I. Togo, V. Terleev, A. Nikonorov, Yu. Volkova, "Analysis of stress-strain state rainfall runoff control system buttress dam", Procedia Engineering, vol. 165, pp. 1619-1628, 2016.

[25] C.E. Mirtskhulava, "Calculation of the expedient term of the exploitation of soils", J. Reports of the Russian Academy of Agricultural Sciences, vol. 1, pp. 20-34, 1995.

[26] V.I. Olgarenko, G.V. Olgarenko, I.V. Olgarenko, "Integrated assessment of the technical level of the irrigation and drainage systems", Melioration and water management, vol. 6, pp. 8-11, 2013.

[27] L.L. Shishov, "Criteria and Models of Soil Fertility", Moscow, p. 187, 1987.

[28] F.K. Abdrazakov, N.F. Ryzhko, S.N. Ryzhko, S.A. Horin, S.V. Botov, "Electricity consumption decrease at pump stations during watering by multi-support sprinkling units", Journal of Fundamental and Applied Sciences, vol. 10, pp. 1464-1481, 2018.

[29] V.A. Volosukhin, M.A. Bandurin, V.V. Vanzha, A.V. Mikheev, Y.V. Volosukhin, "Numerical analysis of static strength for different damages of hydraulic structures when changing stressed and strained state", Journal of Physics: Conference Series, 1015(4), 2018, 042061.

[30] O.G. Degtyareva, D.A. Dac'o, G.V. Degtyarev, A.D. Gumbarov, "Design in cae system of low-head weir tiled foundation sinking", Proceedings of the Kuban State Agrarian University, vol. 64, pp. 221226, 2017. 